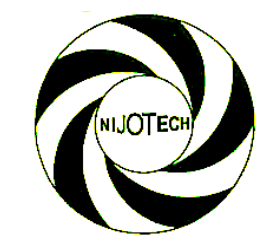

Nigerian Journal of Technology (NIJOTECH)

Vol. 39, No. 1, January 2020, pp. 97 - 104

Copyright@ Faculty of Engineering, University of Nigeria, Nsukka,

Print ISSN: 0331-8443, Electronic ISSN: 2467-8821

www.nijotech.com

http://dx.doi.org/10.4314/njt.v39i1.10

\title{
EFFECTS OF GROUND GRANULATED BLAST FURNACE SLAG AND PULVERIZED FUEL ASH ON RHEOLOGY OF CONCRETE
}

\author{
A. S. Bature ${ }^{1, *}$, M. Khorami ${ }^{2}$ and A. Lawan ${ }^{3}$ \\ 1, 2, Centre for Research in Built and Natural EnV., Coventry University, CV1 5FB, UNITED Kingdom \\ 3, Department of Civil Engineering, Ahmadu Bello University ZARIA, KAduna State, NIGERIA \\ E-mail addresses; ${ }^{1}$ shinkafa@uni.coventry.ac.uk, ${ }^{2}$ aa8186@coventry.ac.uk, ${ }^{3}$ bnlawan@yahoo.co.uk
}

\begin{abstract}
The rheology of concrete containing Pulverized Fuel Ash (PFA) and Ground Granulated Blast Furnace Slag (GGBS) has been scarcely studied and reported, despite their increase application as Supplementary Cementitious Materials (SCM) that drives improvement of sustainability of the construction industry. This work studied the effect of these SCMs and Superplasticizer proportions on rheological properties of concrete using rate controlled concrete rheometer. Two groups of mixes containing replacement or addition on mass basis using either PFA or GGBS or their combinations were derived from the control mix. The dynamic yield stress, plastic viscosity and 28 day compressive strength of the control mix are $1258 \mathrm{~Pa}, 6 \mathrm{PaS}$, and $40.5 \mathrm{MPa}$ respectively. The results of the rheology tests of the various binary mixes (PFA and Portland cement) and ternary mixes (Portland cement, PFA and GGBS) structural concrete shows wide disparity in the measured rheological parameters. The results show that the decrease in dynamic yield stress of the ternary mix containing $20 \%$ GGBS is $4.1 \%$, whereas the decrease in dynamic stress of the ternary mix containing $20 \%$ PFA is $35.9 \%$ compared to the control ternary mix. The high volume Portland cement replaced ternary concrete can therefore be effectively characterized as a workable and pumpable concrete.
\end{abstract}

Keywords: Rheology, PFA, GGBS, superplasticizer, concrete.

\section{INTRODUCTION}

Cement is a basic constituent of concrete and is the largest manufactured product on earth by mass [1]. About 4.2 billion tonnes of ordinary Portland cement (OPC) was produced in 2016 [2]. High global warming potential and poor durability performance in aggressive environmental conditions are associated with OPC production and usage [3]. According to [1] around 5\% of global $\mathrm{CO}_{2}$ emission is attributed to OPC production and the major strategy towards improving sustainable use of OPC is the use of mineral admixtures either for blending with clinker or as Supplementary Cementitious Material (SCM).

Mineral admixtures are reactive industrial by-product that possess either pozzolanic or cementitious or both properties. Appropriate use of mineral admixtures in concrete improve its long-term strength and durability to aggressive conditions [4]. These materials react with the excess lime produced from hydration reaction of
OPC presented in Equation1 to form additional Calcium Silicate Hydrate (C-S-H) gel presented in Equation 2. However, this gel has lower Calcium to Silicate ratio (C:S) compared to that produced by the hydration of alite and belite thereby enhancing its binding strength due to its high silicate content.

Common mineral admixtures that are been extensively used as SCM are PFA and GGBS of adequate quality. PFA is a by-product collected from electrostatic precipitation of flue gases released during the combustion of coal at coal thermal power stations, while GGBS is processed from molten slag which is a by-product of pig iron blast furnace production and is predominantly composed of non-metallic residue such as quick lime, silica and alumina [5]. According to [6], more than $90 \%$ of the GGBS currently produced globally is being used either for the production of blended cement or as SCM. 
$2(\mathrm{CaO})_{3} \cdot\left(\mathrm{SiO}_{2}\right)+7 \mathrm{H}_{2} \mathrm{O} \longrightarrow(\mathrm{CaO})_{3}\left(\mathrm{SiO}_{2}\right)_{2} \cdot 4\left(\mathrm{H}_{2} \mathrm{O}\right)+3 \mathrm{Ca}(\mathrm{OH})_{2} \ldots$

$\mathrm{AS}_{2}+\mathrm{CH}+\mathrm{zH}$

$\mathrm{CSHz}-5+\mathrm{C}_{2} \mathrm{ASH}_{8} \ldots .$.

Up to $50 \%$ replacement of OPC with GGBS have proven to improve mechanical and durability properties of concrete, while slowing the early age strength development [7]. However, [1] reported that GGBS and PFA production of adequate quality are limited globally to only about $15-25 \%$ of cement consumption and are not likely to increase. It is therefore critical to ensure efficient utilization of these SCMs in order to continue improving the sustainability of the construction industry.

Efficient use of these SCMs can be improved through understanding the rheological behaviour of the concrete that are commonly measured using single point tests such as slump tests, flow tests etc. However, these tests are generally simple, rapid and empirical but cannot provide the basic information of concrete rheology that are necessary in developing an efficient mix containing SCM [8]. The Rheology tests enables detail quantitative measurement and characterizes properties of fresh concrete such as workability loss, stability, compatibility and flow behaviour, and it's been scarcely studied for concrete generally, especially when SCM and superplasticizers are introduced into the mix [9].

The wide range of particle sizes and time dependent properties of fresh concrete complicate the characterization of its rheological properties according to the common models for characterization of fluids. Banfil [10] reported that fresh concrete is mostly considered to follow the Bingham model due to its possession of yield stress values and the linear relationship between its shear stress and shear rate as per Equation 3. Concrete is also reported not to show structural breakdown over the range of shear rates in the common test methods.

$$
\mathrm{T}=\mathrm{T}_{0}+\mu \mathrm{N}
$$

Where; $\tau$ is the shear stress; $\tau_{0}$ is the yield stress; $\mu$ is the plastic viscosity; $\mathrm{N}$ is the shear rate

Rheological parameters of concrete containing SCMs are influenced by various factors such as water: cement ratio, specific surface area, shape, surface features, type of cement and admixtures used [11]. Ferraris [12] reported that, varied flows is obtained from the same mixture design based on the above variables alone, but which do not consider secondary factors such as mixer type, mixing sequence, duration and temperature.
Laskar and Talukdar, [11] reported a decrease in both the yield stress and plastic viscosity of concrete due to replacement of cement with PFA. The study however showed slight increase in yield stress at higher replacement levels up to $30 \%$ replacement level, while the effect on plastic viscosity was insignificant. According to [13], plastic viscosity of concrete is the most relevant rheological parameter for characterization of its Bingham behaviour.

In this study, rheological behaviour of concrete incorporating varied content of PFA, GGBS and superplasticizer was studied experimentally using rate controlled concrete rheometer developed by International Centre for Aggregate Research (ICAR). The effects of these SCMs proportion were studied when used either as replacement or additional binder in the concrete mix. The results obtained from the various experiments were compared with that of the control structural concrete mix.

\section{MATERIALS AND METHODS}

\subsection{Material}

High strength EN $52.5 \mathrm{~N}$ Portland cement conforming to BS EN 197-1 was used in all the mixes. BS EN 151671 compliant GGBS supplied by Hanson Cement Ltd from their Teeside plant and PFA that complies with BS EN 450-1:2005 fineness category $N$ were used as the SCMs in this study. Polycarboxylate ether produced by Forsoc Itd was used as the superplasticizer. Sharp sand finer than $4.5 \mathrm{~mm}$ sieve size and uncrushed aggregate of 10 $\mathrm{mm}$ maximum size obtained from local suppliers were used for all the concrete mixes. The coarse aggregate has specific gravity, crushing value and water absorption of $2.65,23.5 \%$ and 0.6 respectively. The grading curve of the coarse aggregate is presented in Figure 1.

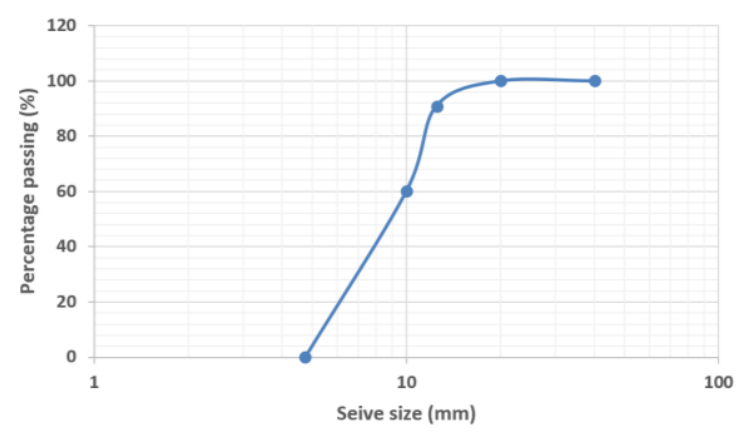

Fig. 1: Particle size distribution curve of the coarse aggregate 
Table 1: Groups of Mixture proportions of $1 \mathrm{~m}^{3}$ structural concrete

\begin{tabular}{|c|c|c|c|c|c|c|c|}
\hline & $\begin{array}{l}\text { OPC } \\
(\mathrm{kg})\end{array}$ & $\begin{array}{l}\text { PFA } \\
(\mathrm{kg})\end{array}$ & $\begin{array}{l}\text { GGBS } \\
(\mathrm{kg})\end{array}$ & $\begin{array}{l}\text { Water } \\
(\mathrm{kg})\end{array}$ & $\begin{array}{l}\text { Fine Agg. } \\
(\mathrm{kg})\end{array}$ & $\begin{array}{l}\text { Coarse Agg. } \\
(\mathrm{kg})\end{array}$ & \\
\hline Control Mix & 404.2 & 0 & 0 & 220.8 & 920.8 & 725 & \\
\hline PFA - R5\% & 383.99 & 20.21 & 0 & 220.8 & 920.8 & 725 & \\
\hline PFA - R10\% & 362.5 & 41.7 & 0 & 220.8 & 920.8 & 725 & \\
\hline PFA - R15\% & 343.57 & 60.63 & 0 & 220.8 & 920.8 & 725 & \\
\hline PFA - A5\% & 404.2 & 20.8 & 0 & 220.8 & 920.8 & 725 & \\
\hline PFA - A10\% & 404.2 & 41.7 & 0 & 220.8 & 920.8 & 725 & \\
\hline PFA - A $15 \%$ & 404.2 & 58.3 & 0 & 220.8 & 920.8 & 725 & \\
\hline \multicolumn{8}{|c|}{ Group 2: Mixes containing varied proportion of PFA and GGBS using constant aggregate content } \\
\hline & $\begin{array}{l}\text { OPC } \\
(\mathrm{kg})\end{array}$ & $\begin{array}{l}\text { PFA } \\
(\mathrm{kg})\end{array}$ & $\begin{array}{l}\text { GGBS } \\
(\mathrm{kg})\end{array}$ & $\begin{array}{l}\text { Water } \\
(\mathrm{kg})\end{array}$ & $\begin{array}{l}\text { Fine Agg. } \\
(\mathrm{kg})\end{array}$ & $\begin{array}{l}\text { Coarse Agg. } \\
(\mathrm{kg})\end{array}$ & $\begin{array}{l}\text { WRA } \\
(\mathrm{L})\end{array}$ \\
\hline Control Mix & 404.2 & 0 & 0 & 220.8 & 654.2 & 800 & 0 \\
\hline PFA-R5\% GGBS-R10\% & 320.8 & 20.8 & 37.5 & 220.8 & 654.2 & 800 & 0 \\
\hline PFA-R10\% GGBS-R15\% & 283.3 & 37.5 & 58.3 & 220.8 & 654.2 & 800 & 0 \\
\hline PFA-R15\% GGBS-R20\% & 245.8 & 58.3 & 75 & 220.8 & 654.2 & 800 & 0 \\
\hline PFA-R15\% GGBS-R10\% & 283.3 & 58.3 & 037.5 & 220.8 & 654.2 & 800 & 0 \\
\hline PFA-R20\% GGBS-R15\% & 245.8 & 75 & 58.3 & 220.8 & 654.2 & 800 & 0 \\
\hline PFA-R20\% GGBS-R25\% & 208.3 & 75 & 95.8 & 220.8 & 654.2 & 800 & 0 \\
\hline PFA-R20\% GGBS-R20\% & 229.2 & 75 & 75 & 220.8 & 654.2 & 800 & 0 \\
\hline PFA-R25\% GGBS-R20\% & 208.3 & 95.8 & 75 & 220.8 & 654.2 & 800 & 0 \\
\hline $\begin{array}{l}\text { PFA-R20\% GGBS-R25\% WC-D5\% } \\
\text { PFA-R20\% GGBS-R20\% WC- }\end{array}$ & 208.3 & 75 & 95.8 & 208.3 & 654.2 & 800 & 0.833 \\
\hline $\begin{array}{l}\text { D10\% } \\
\text { PFA-R25\% GGBS-R20\% WC- }\end{array}$ & 229.2 & 75 & 75 & 200 & 654.2 & 800 & 1.2 \\
\hline D15\% & 208.3 & 95.8 & 75 & 187.5 & 654.2 & 800 & 1.7 \\
\hline
\end{tabular}

R: replacement; A: addition; D: Decrease

\subsection{Preparation of concrete sample}

Control mix was designed according to Building Research Establishment (BRE) method for normal concrete mixes with targeted mean compressive strength of $35 \mathrm{MPa}$ at 28 days, slump of $80 \mathrm{~mm}, 10$ $\mathrm{mm}$ maximum size for uncrushed coarse aggregate and $35 \%$ passing sieve $600 \mu \mathrm{m}$ fine aggregate. Two groups of mixes containing either replacement or addition on mass basis using either PFA or GGBS or their combinations were derived from the control concrete mix. These mixes are presented in table 1 and were prepared in a horizontal concrete mixer for various tests.

Upon completion of the rheology tests using ICAR rate controlled concrete rheometer, the fresh concrete from all the mixes were poured into $100 \times 100 \mathrm{~mm}$ plastic moulds in 3 layers and compacted using a vibrating table. The surface of the cube was flattened and then allowed to harden at room temperature for 24 hrs. The cubes were then demoulded and placed in a curing tank until the testing age of 7, 14 and 28 days.
For example PFA-R25\% GGBS- R20\% WC-D15\% means 25\% PFA replacement of Portland cement $20 \%$ GGBS replacement of Portland cement $-15 \%$ decrease in water content.

\subsection{Tests}

The consistency and rheological behaviour for each mix were studied to determine the effect of the PFA and GGBS proportion on the concrete, and their influence on compressive strength development.

\subsubsection{Slump Test for the concrete mixes}

The slump test for each mix was carried out in accordance with BS EN 12350-2:2009 specification to determine the consistency of the fresh concrete mix.

\subsubsection{Stress Growth Test}

The Stress Growth Test (SGT) was carried out using ICAR rate controlled concrete rheometer based on the specification of the manufacturer. For the SGT, 0.024 $\mathrm{m}^{3}$ of fresh concrete was placed in the ICAR concrete 
rheometer to determine the static yield stress. The rotational speed of the vane was set at $0.025 \mathrm{rps}$ and was applied to the concrete materials for at least 40 seconds. The peak torque and static yield stress of the concrete were computed using Equation 4.

$$
\mathrm{T}_{\mathrm{o}}=\frac{2 \mathrm{~T}}{\pi D^{3}\left(\frac{H}{D}+\frac{1}{3}\right)}
$$

Where $T_{o}$ is the yield stress; $T$ is the maximum torque; $\mathrm{H}$ and $\mathrm{D}$ are the height and diameter of the vane.

\subsubsection{Flow Curve Test}

The Flow Curve Test (FCT) was carried out to determine the relationship between the shear stress and shear rate using the ICAR rate controlled concrete rheometer based on the manufacturer's specification, by obtaining the dynamic yield stress and plastic viscosity of the fresh concrete sample. The test commenced from a pre-shear period followed by a set of flow curve points to reduce the effect of thixotropy and provide a consistent shear history. During the preshear period, the vane maintained a constant high speed equal to the maximum test speed without recording any measurement. The flow curve then follows the pre-shear period with the speed of the vane in a descending order by following the number of points. The test was calibrated such that, the breakdown time was 20 seconds, initial speed of 0.5 rps, final rotational speed of 0.05 rps and the numbers of points was set at 7 points. The speed points are divided between the initial and final speed points. The value of dynamic yield stress and plastic viscosity for the fresh concrete that is considered to be within the annulus flow were then computed using the Bingham equation expressed in Equation 3 and Reiner-Riwlin equation expressed in Equation 5.

$$
\Omega=\frac{T}{4 \pi h \mu}\left(\frac{1}{R_{1}^{2}}-\frac{1}{R_{2}^{2}}\right)-\frac{\tau_{o}}{\mu} \ln \left(\frac{R_{2}}{R_{1}}\right)
$$

Where $\Omega$ is the rotation speed ( $\mathrm{rad} / \mathrm{s}) ; T$ is the torque $(\mathrm{Nm}) ; h$ is the vane height $(\mathrm{m}) ; R_{1}$ is the vane radius; $R_{2}$ is the outer container radius.

\subsubsection{Compressive Strength Development Test}

The compressive strength development tests for the saturated dry surface $100 \times 100 \mathrm{~mm}$ concrete cubes sample for each of the mixes were carried out in accordance with BS EN 12390-3:2009. The tests were carried out using Avery Denison 2000 compressive strength testing machine and the loading rate was set at $0.8 \mathrm{MPa} / \mathrm{s}$.

\subsubsection{Scan Electron Microscopy Probe}

Microstructure of three pastes based on Portland cement only, binary mix of Portland cement and PFA, and ternary mix of Portland cement, PFA and GGBS were probed using SEM. The various $50 \mathrm{~mm} \times 50 \mathrm{~mm}$ cubes were cured for 28 days, crushed to obtain small samples of not more than $10 \mathrm{~mm}$ thickness and the fracture surface were examined using a Philip XL-30 instrument. Different micrographs that reveal the morphology of the hydration products were obtained.

\section{RESULTS AND DISCUSSION}

Rheological properties of the various binary mixes (PFA and Portland cement) and ternary mixes (Portland cement, PFA and GGBS) structural concrete studied in this work showed wide disparity in terms of increase or decrease trend in the measured rheological parameters due to some reasons elucidated in the subsequent sub-section of this paper.

\subsection{Group 1}

\subsubsection{Effect of PFA proportion on consistency of structural concrete}

Slump value of $160 \mathrm{~mm}$ was measured for the Group 1 control mix concrete due to the high W:C of 0.55 of the mix. A consistent decrease in slump height of the group 1 mixes was observed while decreasing the water:cementitious material ratio (W : (C + PFA) from 0.55 to 0.48 through addition of PFA content from $5 \%$ to $15 \%$ as shown in Figure 2. However, increased consistency of the concrete was observed up to $15 \%$ replacement of OPC with PFA while using W: (C+ PFA) of 0.55 due to the spherical shape of the PFA that enhances the flowability of the concrete. Another reason is the low Ca content and coarser surface area of the PFA compared to Portland cement which delays the pozzolanic reaction thereby increasing the setting time of the concrete.

For the $15 \%$ PFA addition mix, the slump height is 110 $\mathrm{mm}$ as shown in Figure 2 and is a true slump based on BS EN 12350 - 2 that specifies $80-110 \mathrm{~mm}$ for any true slump. The increase binder content of the mix due to addition of PFA which decrease the W: (C+ PFA) results in decreasing the consistency of the concrete due to PFA addition. 


\subsubsection{Effect of PFA proportion on compressive strength development of structural concrete (Group 1)}

Compressive strength gain was observed for all the mixes with increase in age of the concrete due to continuity of hydration reaction of the binder under water curing condition. The least strength of 22.09 MPa was observed at 7 days for the mix containing 15\% PFA replacement content as shown in Figure 3. The low strength of this mix at 7 days is due to very high water and PFA content that delayed the rate of early hydration reaction, since binary mix of Portland cement and PFA always require lower water: binder ratio, as concluded by [7]. At 28 days, all the mixes produced a concrete that is suitable for use as structural concrete that requires a compressive strength of between $20-50 \mathrm{MPa}$.

Increase in binder content through addition of PFA and corresponding decrease in W: (C+PFA) shows a trend of compressive strength gain for the mixes in group 1 . The added PFA react with the lime produced from the hydration reaction to produce additional hydrate of calcium silicate, thereby enhancing the strength of the binding phase of the concrete. On the other hand, mixes with PFA replacement content between $10 \%$ and $15 \%$ and $\mathrm{W}:(\mathrm{C}+\mathrm{PFA})$ of 0.55 results in decrease in compressive strength of the concrete compared to the control mix as shown in Figure 3. The replacement of Portland cement with PFA decreased the amount of $\mathrm{C}-\mathrm{S}-\mathrm{H}$ gel and $\mathrm{Ca}(\mathrm{OH})_{2}$ produced from the hydration reaction. As a result of decreased amount of lime produced, not all the PFA reacts with the portlandite thereby resulting in the decrease in the strength of the binding phase of the concrete.

\subsection{Group 2}

\subsubsection{Effect of PFA and GGBS replacement} proportion on rheological behaviour of ternary mix structural concrete (Group 2)

The static yield stress that initiate flow of concrete is greater than the dynamic yield stress that ensure continuous flow of concrete for all the group 2 concrete mixes. Concrete mixes with more GGBS than PFA content shows higher yield stresses than mixes with more PFA than GGBS content. It was also observed that, the reduction in water content of between $5 \%$ and $15 \%$ of the control concrete mix shows a significant increase in both the static and dynamic yield stresses of the corresponding mix regardless of the PFA and GGBS proportion, as presented in Figure 4. However, addition of WRA for the mixes with decrease in water content influences the measured yield stresses of the concrete.

The yield stresses of the concretes are not only influenced by the water: binder (W: (C+PFA+GGBS)) but also by the proportion of each of the constituent binders. The GGBS proportion shows greater influence on both the static and dynamic yield stresses of the concrete more than the PFA proportion for the mixes compared in Figure 4.

Figure 5 shows that all the ternary mixes have higher plastic viscosity than the control mix concrete. The results further shows that GGBS proportion influences increase in plastic viscosity of the concrete more than the PFA content.

\subsubsection{Effect of PFA and GGBS on compressive strength development of ternary mix structural concrete (Group 2)}

The least compressive strength for 28 day ternary mix concrete is $37.87 \mathrm{MPa}$ for the mix containing 25\% PFA and 20\% GGBS replacement produced with $\mathrm{W}$ :(C+PFA+GGBS) of 0.58 . The 28 days strength of ternary mix concrete increases up to $35 \%$ replacement level. The reduction of water content for replacement level above $35 \%$ greatly increased the compressive strength of the concrete as shown in figure 6 . This finding further confirms that decrease in water content of ternary mix concrete at high Portland cement replacement level is necessary to achieve high strength concrete.

The high strength achieved by this ternary mix despite high volume replacement of Portland cement further confirm the portlandite consumption by the GGBS and PFA to produce additional C-S-H gels that enhance the strength of the binding phase of the concrete. This concur with the findings of [14] that pozzolans improve the strength properties of concrete. Moreover, the GGBS grains require lime to continue their hydration reaction due to their high Ca content, while the PFA grains rely on the $\mathrm{Ca}(\mathrm{OH})_{2}$ primarily to liberate their pozzolanic potential and produce any hydration product.

\subsection{Relationship between Microstructure and Compressive Strength of the Concrete}

Morphology of the cement paste presented in figure 7 plate a shows a dense concentration of C-S-H covered with little pores in the surface which may correspond to the high strength achieved by the control mix. The interconnected crack which propagate across the surface of the cement paste may be due to the load 
applied on the cube to obtain a $10 \mathrm{~mm}$ size fractured surface sample. The micrograph of the binary mix paste presented in figure 7 plate $b$ shows the morphology of the hydrated phase to consist of the CS-H gel, hexagonal crystals of monosulfate hydrate and spherical bubble induced by the existing PFA. Some cracks, which may have been caused by the loading of the cube to obtain a fractured surface sample extended beyond the hydration products but are not interconnected as observed in the control paste. Figure 7 plate $b$ also shows a large void which may be the cause of decrease strength observed in the binary mix that has lower Portland cement content due to its $20 \%$ replacement with PFA. Moreover, no hexagonal crystals of portlandite are seen on the surface essentially due to pozzolanic reaction involving the PFA.

Figure 7 plate $c$ shows some dispersed spherical shape bubbles due to the PFA content of the ternary mix paste. The figure also features small disconnected cracks on the spherical surface resulting from the failure load and shows only crystals of C-S-H gel on the surface which may be caused by the consumption of the portlandite in the pozzolanic reaction. These additional C-S-H gels, couple with the dense and compact microstructure of the ternary mix paste in figure 6 plate $c$ is the probable cause of its increase strength.

\section{CONCLUSION}

The rheological properties of the various binary mixes (PFA and Portland cement) and ternary mixes (Portland cement, PFA and GGBS) structural concrete reported in the study showed significant disparity in terms of either increase or decrease in rheological parameters with mix trends observed.

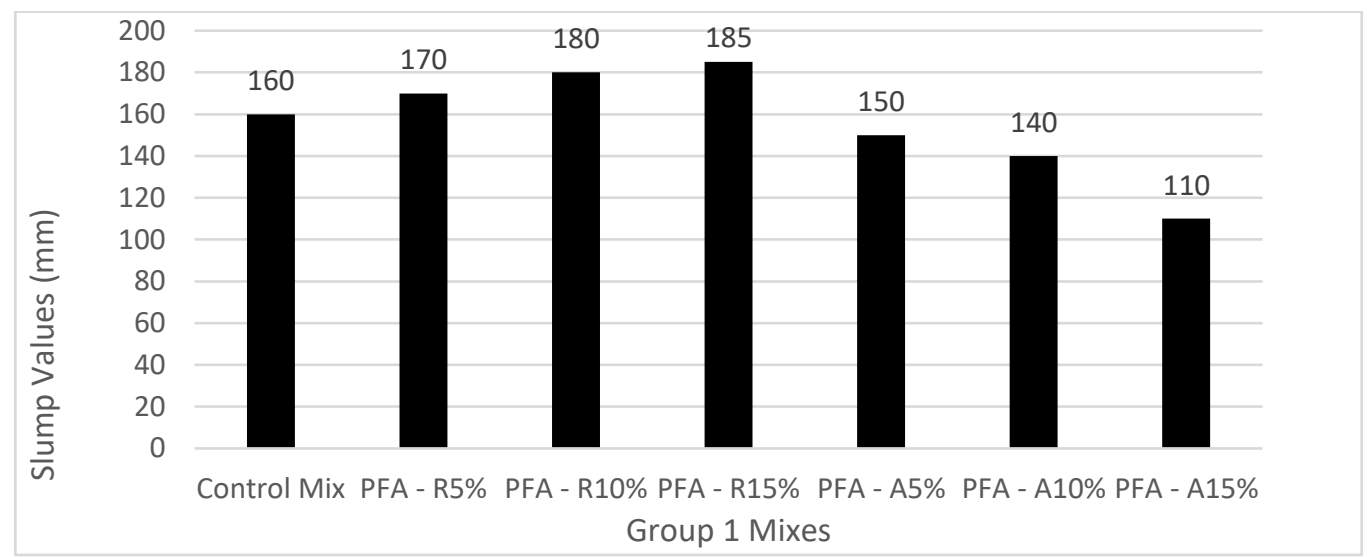

Fig. 2: Slump values against Group 1 concrete mixes

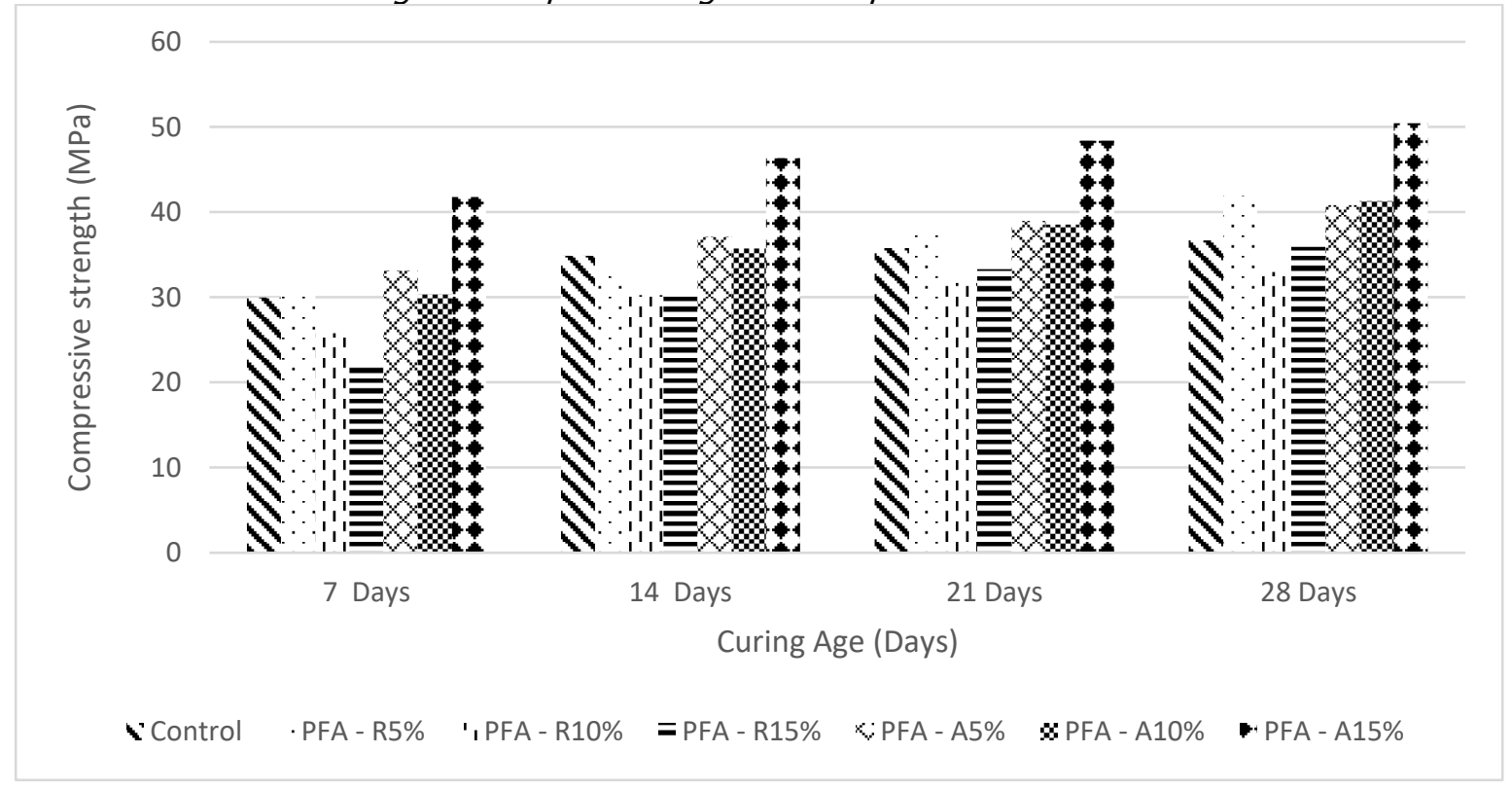

Fig. 3: Comparing compressive strength development of the concrete mixes in Group 1 


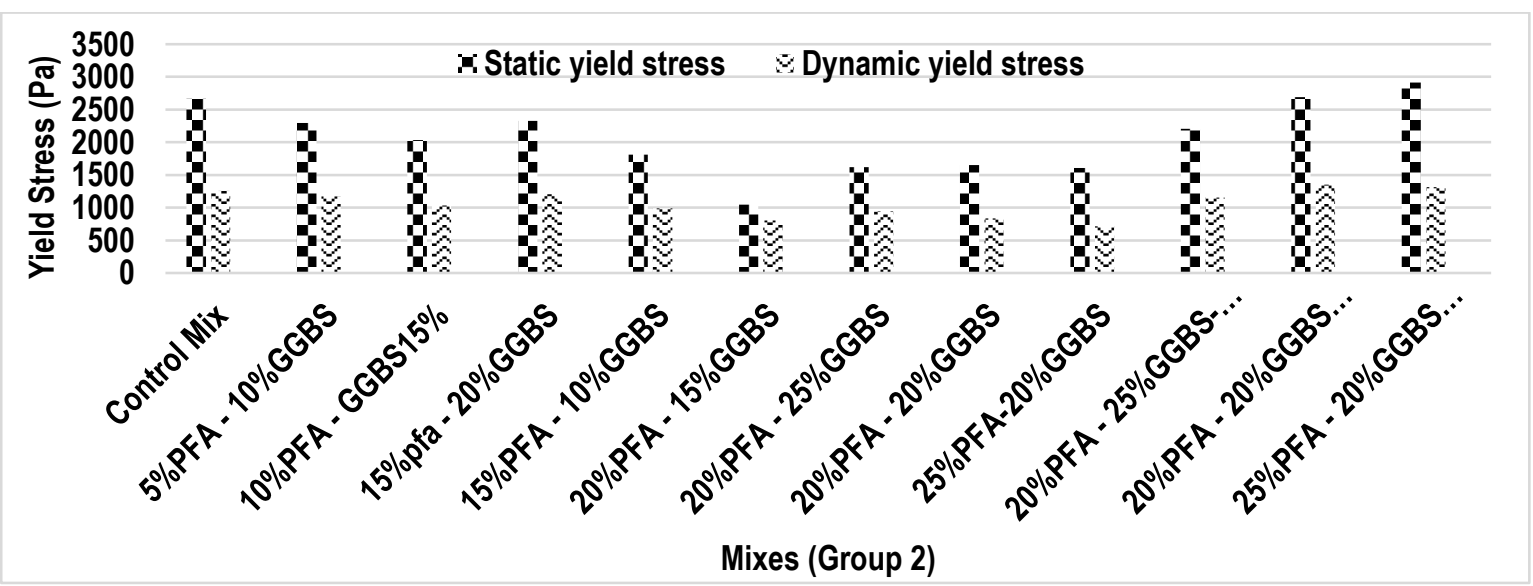

Fig. 4: Static and Dynamic yield stresses against Group 2 Mixes

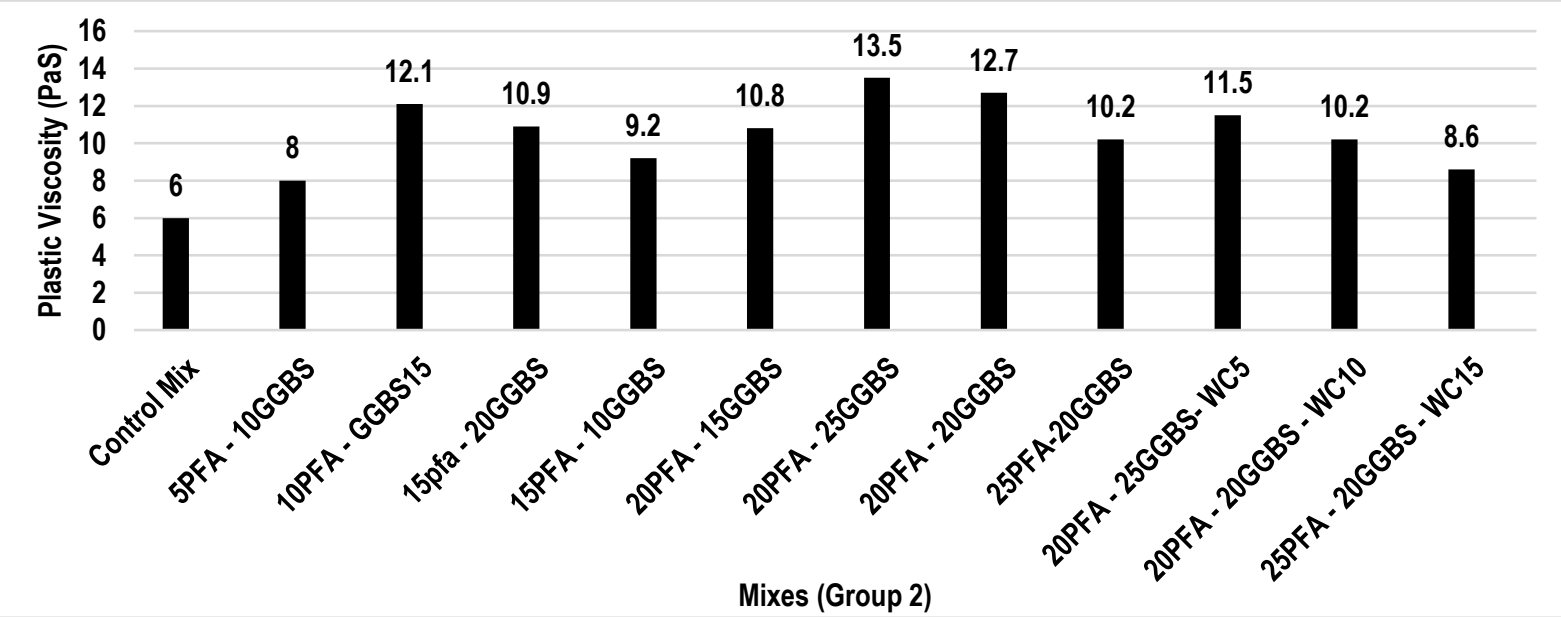

Fig. 5: Plastic Viscosity against concrete mixes (Group 2)

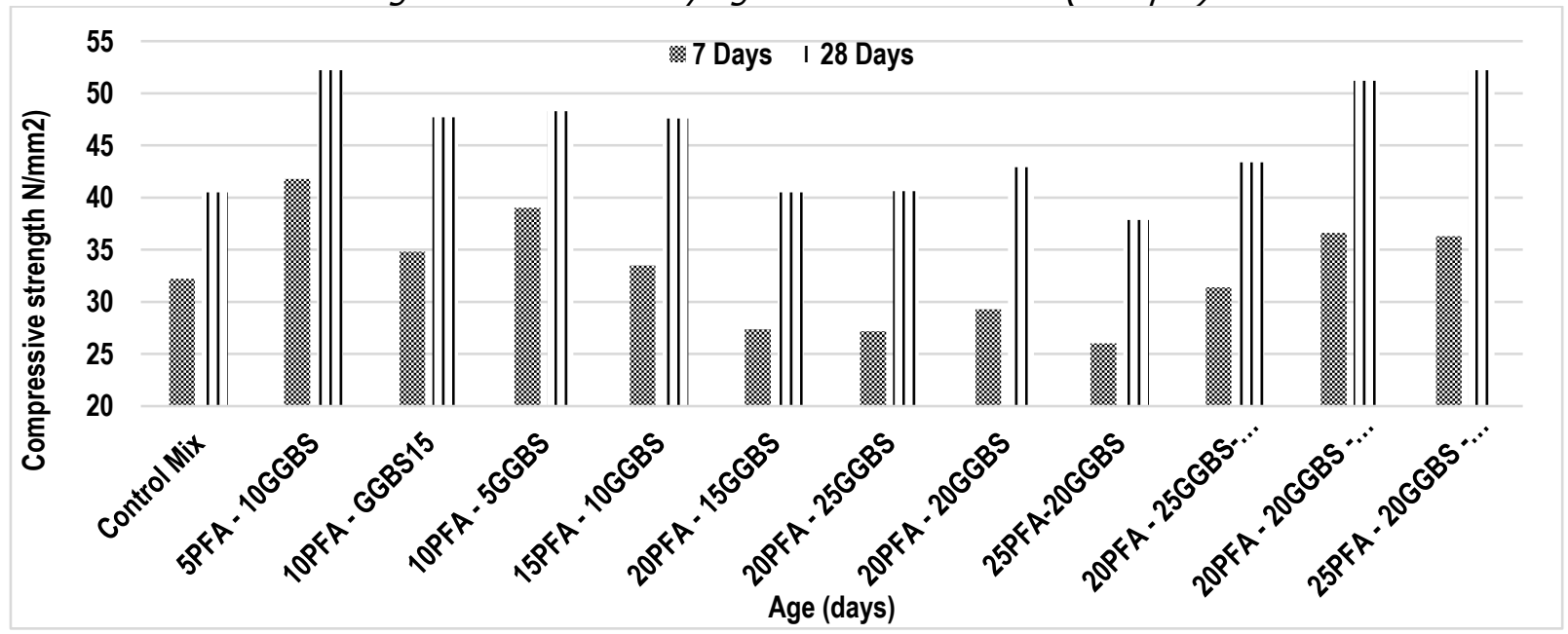

Fig. 6: Compressive strength development against Age for Group 2 Mixes

From the results, it can also be concluded as follows:

1. The dynamic yield stress of fresh concrete is always higher than its static yield stress. Also, a positive linear relationship exist between the yield stress and plastic viscosity of concrete. As such, fresh concrete containing either PFA or GGBS or both can also be characterized as a Bingham fluid.

2. The yield stress and plastic viscosity of ternary mix (Portland cement - PFA - GGBS) concrete are influenced by $\mathrm{W}:(\mathrm{C}+\mathrm{PFA}+\mathrm{GGBS})$ ratio, as well as their proportion in the mix.

3. PFA proportion shows more influence on decreasing the yield stresses of the structural concrete more than the GGBS proportion in the ternary mixes. For instance, at $35 \%$ Portland cement replacement, the decrease in dynamic yield stress of the ternary mix containing $20 \%$ GGBS is $4.1 \%$, whereas the decrease in dynamic stress of the other ternary mix containing $20 \%$ PFA is $35.9 \%$ compared to the control ternary mix. 


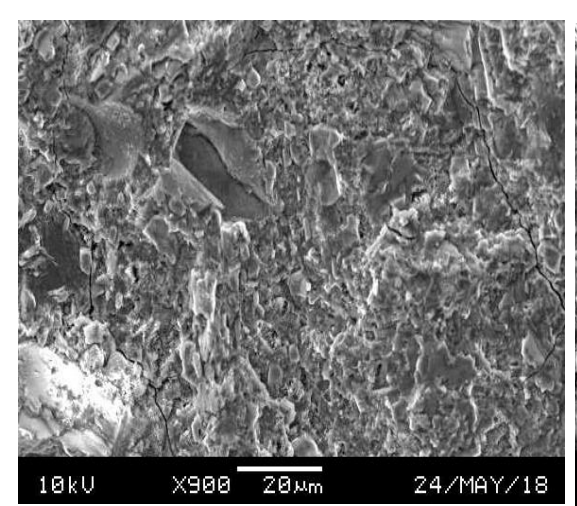

Fig. 7: Secondary Electron image
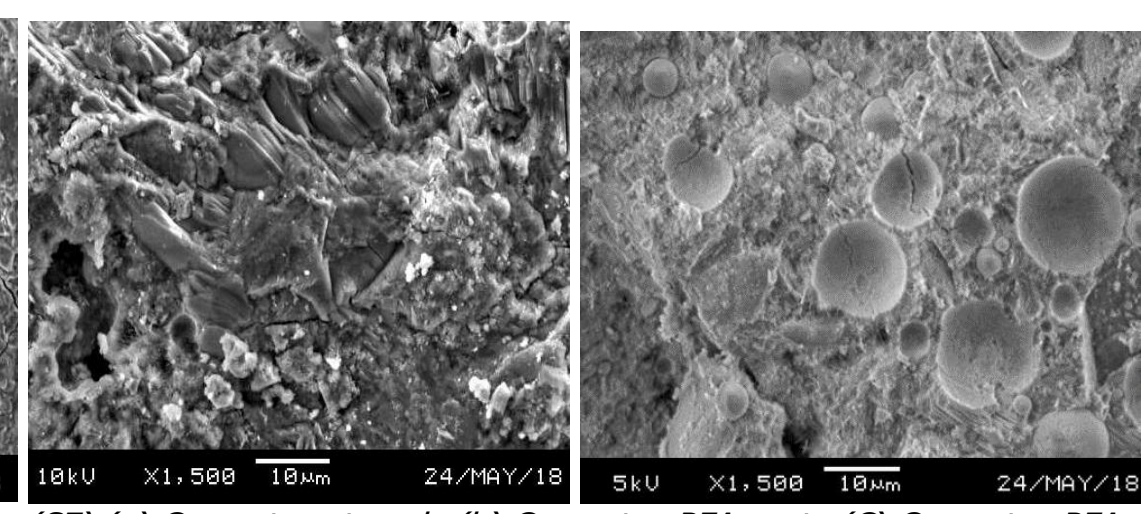
GGBS

4. Polycarboxylate ether based Water Reducing Admixture are very effective in influencing the consistency of concrete containing binary mix $(\mathrm{PFA}+\mathrm{OPC})$ and ternary mix (PFA + GGBS + $\mathrm{OPC})$.

5. The microstructure of the ternary mix paste indicate portlandite consumption due to nonpresence of $\mathrm{Ca}(\mathrm{OH})_{2}$ crystals on the surface.

\section{REFERENCES}

[1]. Scrivener, K., John, V., and Gartner, E. (2016) 'Eco-Efficient Cements: Potential, Economically Viable Solutions for a Low CO2, Cement Based Materials Industry'. United Nations Environment Program, Paris

[2]. Ober, J. A. (2017). Mineral Commodity Summaries 2017. [Online] available from $<$ https://www.usgs.gov/centers/nmic/mineralcommodity-summaries>

[3]. Duxson, P., Provis, J. L., Lukey, G. C., and Van Deventer, J. S. (2007) 'The Role of Inorganic Polymer Technology in the Development of 'green Concrete". Cement and Concrete Research 37 (12), 1590-1597

[4]. Thomas, M. (2013) Supplementary Cementing Materials in Concrete: Taylor and Francis, USA.

[5]. Łukowski, P. and Salih, A. (2015) 'Durability of Mortars Containing Ground Granulated BlastFurnace Slag in Acid and Sulphate Environment'. Procedia Engineering 108, 47-54.

[6]. WBCD, C. S. I. (2014) Getting the Numbers Right [online] available from $<$ http://www.wbcsdcement.org/index.php/keyissues/climate-protection/gnr-database> [2017]
[7]. Claisse, P., A. (2016) Civil Engineering Materials.: Oxford, UK : Butterworth-Heinemann is an imprint of Elsevier

[8]. Laskar, A. I. and Bhattacharjee, R. (2011) 'Rheology of Fly-Ash-Based Geopolymer Concrete.'. ACI Materials Journal 108 (5), 536542.

[9]. Laskar, A. I. and Bhattacharjee, R. (2013) 'Effect of Plasticizer and Superplasticizer on Rheology of Fly-Ash-Based Geopolymer Concrete'. ACI Materials Journal 110 (5), 513-518

[10]. Banfill, P. (2006) 'Rheology of Fresh Cement and Concrete'. Rheology Reviews 2006, 61-68

[11]. Laskar, A. I. and Talukdar, S. (2008) 'Rheological Behavior of High Performance Concrete with Mineral Admixtures and their Blending'. Construction and Building Materials 22 (12), 2345-2354.

[12]. Ferraris, C., De Larrard, F., and Martys, N. (2001) 'Fresh Concrete Rheology: Recent Developments'. Materials Science of Concrete VI, Amer.Cer.Soc.Ed.S.Mindess, J.Skalny, 215241

[13]. Erdoğan, S. T., Martys, N. S., Ferraris, C. F., and Fowler, D. W. (2008) 'Influence of the Shape and Roughness of Inclusions on the Rheological Properties of a Cementitious Suspension'. Cement and Concrete Composites 30 (5), 393402.

[14]. Mbadike, E. M. (2010) 'Effect of metakaolin on concrete produced with a pozzolan'. Nigerian Journal of Technology 29 (3) 